\title{
Laminar MHD Flow in the Entrance Region of a Plane Channel with Dissipation
}

\author{
D. Venkata Rami Reddy ${ }^{1}$, M. Rama Chandra Reddy ${ }^{2}$, B. Rama Bhupal Reddy ${ }^{3}$ \\ ${ }^{1}$ Lecturer in Mathematics, Government Polytechnic College, Anantapur, A.P., India. \\ ${ }^{2}$ Reader in Mathematics, S.K.S.C. Degree College, Proddatur, A.P., India. \\ ${ }^{3}$ Associate Professor in Mathematics, K.S.R.M. College of Engineering, Kadapa, A.P., India.
}

\begin{abstract}
In this paper Laminar MHD flow in the entrance region of a plane channel with dissipation under the influence of transverse magnetic field. The motion of laminar conducting fluid between two parallel plates is considered. The channel has height of $2 \mathrm{a}$ and a width of $\mathrm{d}$. A rectangular coordinate system is placed on channel with the origin at the center of channel at the left hand edge. The flow problem is described by means of partial differential equations and solutions are obtained by the use of a finite difference technique. The velocity, temperature and pressure profiles are shown in graphs and their behaviour is discussed for the different values of magnetic field parameter $M$ and Eckert Number Ek for fixed Prandtl Number Pr.
\end{abstract}

Keywords: Laminar Flow, MHD Plane Channel

\section{Introduction}

Although many solutions are available for fully developed flows, only a few works deal with the development problem. Blasius [11] technique for a plate, obtained the velocity profile for the entrance region by means of a marching process between an upstream and a downstream solution to the differential equations, which describes the system. Bodoia and Osterle [12] solved the entry problem by means of a finite-difference procedure. Hartmann [22] determined the fully developed velocity profile for a conducting fluid, which has the same conditions for Poiseuille flow, imposed on its motion, except for the addition of magnetic field applied across the channel. Nagarajan [28] obtained the velocity and temperature profiles in the entrance region of a plane channel for laminar flow between two parallel plates.

Later, Attia and Kotb [8] studied the steady flow and heat transfer by considering an exponential temperature variation of the viscosity in a Parallel-plates channel; injection velocity in the plates and movement of the upper plate were considered as well. Attia [9] extended the analysis in 4 including the transient term for the flow field. Analysis of the interaction of a magnetic field with other important physical effects for various situations can be found in $[1,2,10,13,20]$ Lima et al [26] investigate Generalized Integral Transform Technique is obtained for the MHD flow and heat transfer of a Newtonian fluid in parallel-plates channels. The study of the effects of frictional heating and distributed heat sources in the fluid on fully developed laminar free convection flow between vertical heated plates, when the temperature of the walls are kept constant or varying linearly along the plate length, has been done by Ostrach [31].

Nanda and Sharma [29] have extended this to a vertical circular pipe. Goren [21] has obtained a similarity solution. Alireza and Sahai [4] studied the effect of temperatures-dependent transport properties on the developing magneto hydrodynamic flow and heat transfer in a parallel plate channel whose walls are held at constant and equal temperatures. Yang and $\mathrm{Yu}$ [37] studied the problem of convective magneto-hydrodynamic channel flow between two parallel plates subjected simultaneously to an axial temperature gradient and a pressure gradient numerically. In their conclusion they have found that an applied transverse magnetic field may reduce the entrance length of the velocity considerably, but has little effect on the temperature development. Seth and Ghosh [34] considered the unsteady hydromagnetic flow of a viscous incompressible electrically conducting fluid in a rotating channel under the influence of a periodic pressure gradient and of uniform magnetic field, which is inclined with the axis of rotation.

An analytical solution to the problem of steady and unsteady hydromagnetic flow of viscous incompressible electrically conducting fluid under the influence of constant and periodic pressure gradient in presence of inclined magnetic field has been obtained exactly by Ghosh [19] to study the effect of slowly rotating systems with low frequency of oscillation when the conductivity of the fluid is low and the applied magnetic field is weak. Borkakati and Chakrabarty [14] investigated the unsteady free convection MHD flow between two heated vertical parallel plates in induced magnetic field. Angel et al [6] studied the heat and mass transfer problem on mixed convection flow over a horizontal plate. The problem of combined heat and mass transfer of an electrically conducting fluid in MHD free convection adjacent to a vertical surface with Ohmic heating and viscous dissipation is analyzed by Chen [15]. He presented the results for the velocity, temperature, 
and concentration distributions, as well as the local skin-friction coefficient, local Nusselt number, and the local Sherwood number.

Ali Chamkha[3] considered the problem of unsteady, two-dimensional, laminar, boundary-layer flow of a viscous, incompressible, electrically conducting and heat-absorbing fluid along a semi-infinite vertical permeable moving plate in the presence of a uniform transverse magnetic field and thermal and concentration buoyancy effects. He solved the problem analytically using two-term harmonic and non-harmonic functions. MHD free convective flow and mass transfer through a porous medium bounded by an infinite vertical porous plate was investigated by Raptis and Kafousias [32]. Das et al, [17] studied free convective steady flow and heat transfer in a viscous incompressible fluid bounded between vertical wavy walls with equal transpiration. Flow of viscous incompressible fluid past semi-infinite parallel plates with variable viscosity was considered by Deka [18]. Orhan Aydin and Avci [30] investigated analytically to predict laminar heat convection in a Couette-Poiseuille flow between two parallel plates with a simultaneous pressure gradient and an axial movement of the upper plate. The effect of the modified Brinkman number on the temperature distribution and the Nusselt number has been discussed for different values of the relative velocity of the upper plate.

Kazuyuki Veno and Shingeki Morioke [24] studied the effects of induced magnetic field and two dimensionality of imposed magnetic field in MHD inductions generator. MHD flow and heat transfer in a rectangular duct with temperature dependent viscosity and Hall effect studied Mohammed Eissa Sayed Ahmed and Hazem Ali Attia [27]. Anjali Devi and Kandasamy [7] studied the effects of chemical reaction, heat and mass transfer on non-linear MHD laminar boundary-layer flow over a wedge with section of injection. Lahjomri et al [25] were studied heat transfer laminar Hartmenn's flow in thermal entrance region with uniform well heat flux. MHD flows of viscoelastic fluids in converging / diverging channels studied Kayvan Sadeghy et al [23]. Amkadhi et al [5] were studied on the exact solutions of laminar MHD flow over a stretching flat plate. Heat transfer characteristics of a MHD laminar jet flowing over a convex surface studied Chion and Kao [16]. Laminar MHD Flow in the Entrance Region of a Plane Channel studied numerically Venkateswarlu et al [36].

In this paper is to study the laminar magneto hydrodynamic flow is solved numerically for various values of the pertinent of the parameters describing the flow. The equations are placed into a finite difference form to enable the essential nonlinearities of the principal equations to be used in the solutions of the problem. The equations of the system are placed in the finite difference form and solved for various magnetic field parameter M, Eckert number Ek, and fixed Prandtl number Pr. Velocity, temperature and pressure curves are presented from the results of computational work.

\section{Formulation Of The Problem}

The motion of a laminar conducting fluid between two parallel plates is considered. The channel has a height of $2 \mathrm{a}$ and a width of $\mathrm{d}$. It is of an arbitrary length, but the length must be long compared with the development length and the height. The fluids will entire the channel on the left in the figure 1. A rectangular co-ordinate system is placed on channel with the origin at the center of the channel at the left-hand edge. The variable $\mathrm{y}$ increases in an upward direction, and the variable $\mathrm{z}$ increases perpendicularly to both $x$ and $\mathrm{y}$ so as to form a right-handed co-ordinate system. The velocity and temperature profiles develop towards the direction of increasing $x$. A uniform magnetic field of strength $\mathrm{H}_{0}$, is applied in the positive $\mathrm{y}$-direction from bottom to top of the channel.

The governing equations are

$$
\begin{aligned}
& \frac{D \rho}{D t}+\rho \nabla \bullet \bar{q}=0 \\
& \rho \frac{D \bar{q}}{D t}=-\nabla p+\mu \nabla^{2} \bar{q}+\mu_{e} \bar{J} \times \bar{H}+\bar{F}
\end{aligned}
$$

Where $\bar{F}=$ Body force

$$
\rho C_{p} \frac{D T}{D t}=\kappa \nabla^{2} T+\mu \phi
$$

Where $\phi=$ Dissipation function

$$
=\left(\frac{\partial u}{\partial y}+\frac{\partial v}{\partial x}\right)^{2}+2\left[\left(\frac{\partial u}{\partial x}\right)^{2}+\left(\frac{\partial v}{\partial y}\right)^{2}\right]
$$




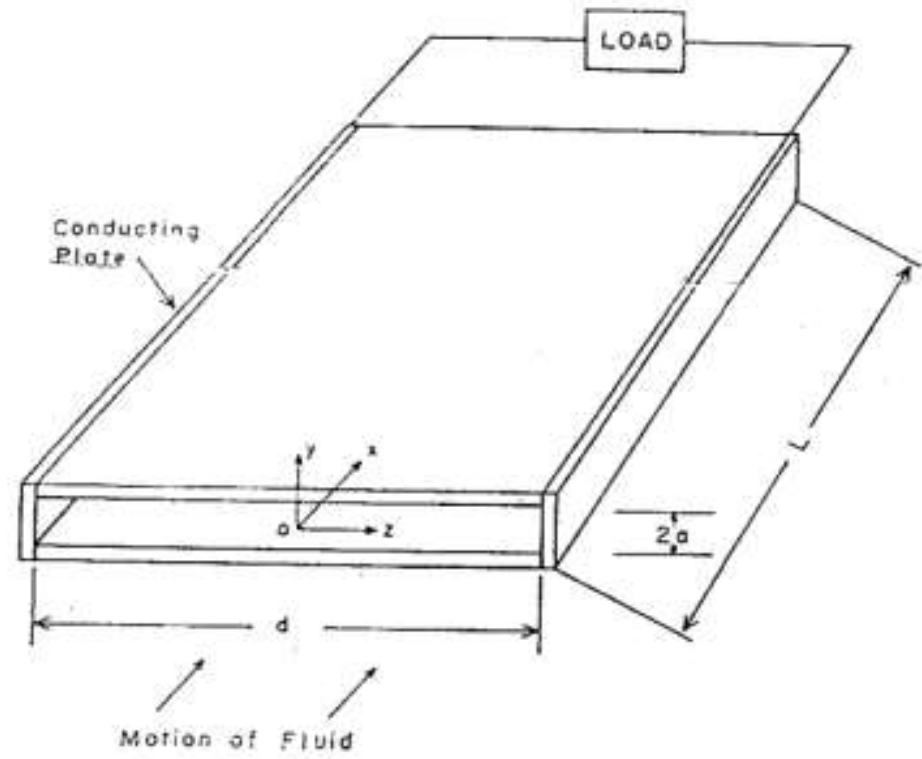

Figure 1: Channel configuration

The Ohm's law is $\bar{J}=\sigma\left[\bar{E}+\mu_{e} \bar{q} \times \bar{H}\right]$

Where $\bar{q}=(u, v, 0)$ and $\bar{H}=\left(0, H_{0}, 0\right)$

The following assumptions are made:

(i) Flow is steady, laminar, viscous, incompressible and developed

(ii) It is assumed that electric field $\bar{E}$ and induced magnetic field are neglected [33, 35]

(iii) All the physical properties of the fluid are assumed to be constant

(iv) It is assumed that body force is neglected.

Using the above assumptions the governing equations become

$$
\begin{aligned}
& \frac{\partial u}{\partial x}+\frac{\partial v}{\partial y}=0 \\
& \rho\left[u \frac{\partial u}{\partial x}+v \frac{\partial u}{\partial y}\right]=\mu \frac{\partial^{2} u}{\partial y^{2}}-\frac{\partial p}{\partial x}-\sigma \mu_{e}^{2} H_{0}^{2} u \\
& \rho C_{P}\left[u \frac{\partial T}{\partial x}+v \frac{\partial T}{\partial y}\right]=\kappa \frac{\partial^{2} T}{\partial y^{2}}+\mu\left(\frac{\partial u}{\partial y}\right)^{2}
\end{aligned}
$$

The boundary conditions are

$$
\begin{array}{ll}
u=u_{0} ; v=0 ; T=T_{\text {in }} & \text { for } x=0 \text { and } 0 \leq \mathrm{y} \leq \mathrm{a} \\
\mathrm{v}=0 & \text { for } x>0 \text { and } \mathrm{y}=0 \\
u=0 ; v=0 ; T=T_{W} & \text { for } x>0 \text { and } \mathrm{y}=\mathrm{a}
\end{array}
$$

A set if dimensionless variables may now be introduced as follows:

$$
\begin{aligned}
& X=\frac{x \mu}{\rho u_{0} a^{2}} \quad Y=\frac{y}{a} \quad U=\frac{u}{u_{0}} \quad V=\frac{\rho v a}{\mu} \quad \operatorname{Pr}=\frac{\mu C_{P}}{\kappa} \\
& E k=\frac{u_{0}^{2}}{C_{P}\left(T_{w}-T_{i n}\right)} \quad P=\frac{p}{\rho u_{0}^{2}} \quad \theta=\frac{\left(T-T_{i n}\right)}{\left(T_{W}-T_{i n}\right)} M^{2}=\frac{\sigma \mu_{e}^{2} H_{0}^{2}}{\mu}
\end{aligned}
$$

The determining equations are then:

$$
\frac{\partial U}{\partial X}+\frac{\partial V}{\partial Y}=0
$$




$$
\begin{aligned}
& U \frac{\partial U}{\partial X}+V \frac{\partial U}{\partial Y}=\frac{\partial^{2} U}{\partial Y^{2}}-\frac{d P}{d X}-M^{2} U \\
& U \frac{\partial \theta}{\partial X}+V \frac{\partial \theta}{\partial Y}=\frac{1}{\operatorname{Pr}} \frac{\partial^{2} \theta}{\partial Y^{2}}+E k\left(\frac{\partial U}{\partial Y}\right)^{2}
\end{aligned}
$$

The boundary conditions are

$$
\begin{aligned}
& \mathrm{U}=1, \quad \mathrm{~V}=0, \quad \theta=0 \\
& \mathrm{~V}=0 \\
& \mathrm{U}=1, \quad \mathrm{~V}=0, \quad \theta=1
\end{aligned}
$$

for $\mathrm{X}=0$ and $0 \leq \mathrm{Y} \leq 1$

for $\mathrm{X}>0$ and $\mathrm{Y}=0$

for $\mathrm{X}>0$ and $\mathrm{Y}=1$

A finite difference technique is adopted for solving the above equations 9 to 11 together with boundary conditions equation 12

\section{Results and Discussion}

The following initial values are taken at entrance:

$\mathrm{X}=0, \mathrm{U}=1.0 ; \mathrm{V}=0, \mathrm{P}=0.135$ and $\operatorname{Pr}=0.1$. Calculations have been carried out until a fully developed flow is obtained for different values of $\mathrm{M}$ and Ek for fixed Pr, the velocity profiles are shown in figures 2 to 11 , the temperature profiles are shown in figures 12 to 17 and pressure profiles are shown in figures 18 to 19 .

The Magnitude of the velocity reduces with increase the variable parameter $\mathrm{Y}$ by fixing the other parameters and there is no induced magnetic field (Figure 2). When we introduced the magnetic field the similar behaviour of the velocity components is observed for $M=2,4$ and 6 (Figures 3, 4 and 5). Next we observe that velocity profile for $\mathrm{Y}=0.2$ level with increasing the magnitude of the velocity components decreases with increase in the magnitude parameter $\mathrm{M}$ at $\mathrm{Y}=0.6$ level and fixing the other parameters. When we increase the level of $\mathrm{Y}$, the similar behaviour of the velocity components is observed with increasing the magnetic parameter $\mathrm{M}$. The magnitude of the velocity components enhances $0 \leq \mathrm{Y} \leq 0.5$ for the values of $\mathrm{Y}$, and decreases for the values of $0.6 \leq \mathrm{Y} \leq 0.9$ with increase in the variable parameter $\mathrm{X}$ while fixing the other parameter, there is no induced magnetic field $\mathrm{M}$. The velocity profiles are not effects for increasing Eckert number Ek and for fixed magnetic field parameter.

From Figures 12(a) we notice that the temperature enhances with increasing the variances of variable parameter $\mathrm{Y}$ and for $\mathrm{M}=0$. The similar behavior is observed for the intensity of the magnetic field $\mathrm{M}=2$ and 6 (Figures 13(a) and 14(a)). The temperature distribution at various levels of $\mathrm{Y}$ with increasing magnetic parameter $\mathrm{M}$ for different Eckert number Ek, we observe that the temperature decreases with increase in the magnetic intensity of magnetic field $\mathrm{M}$ at $\mathrm{Y}=0.3$ level. When we increase the level of $\mathrm{Y}$, the similar behaviour was observed with increasing the intensity of the magnetic field. The temperature profiles are effect for increasing Eckert number Ek and for fixed magnetic field parameter. Temperature increases for increasing Eckert number Ek and for fixed magnetic field parameter M.

Figures 18 and 19 showing that the magnitude of the pressure component reduces for all values of $\mathrm{X}$ with increasing the intensity of the magnetic field parameter $\mathrm{M}$ and fixing $\mathrm{Y}$, while the magnitude of pressure decreases for $0 \leq X \leq 0.004$ and enhances for $0.006 \leq X \leq 0.02$ with enhancing the magnetic filed parameter $M$ and for fixed Y. The pressure profiles are not effect for increasing Eckert number Ek and for fixed magnetic field parameter.

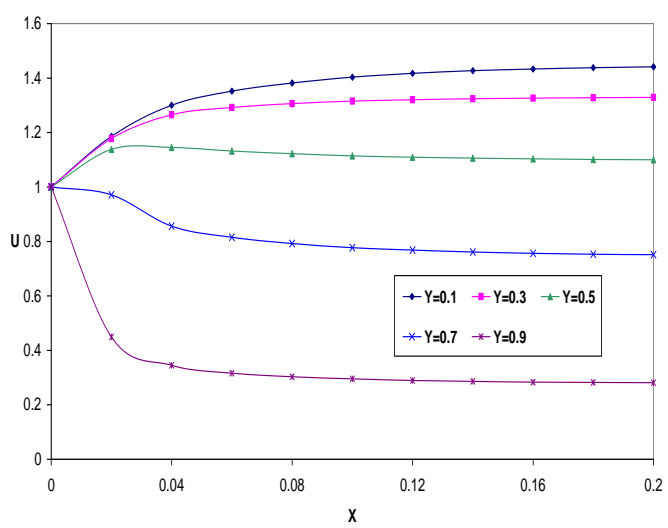

Figure 2: Velocity profile for fixed $M=0$

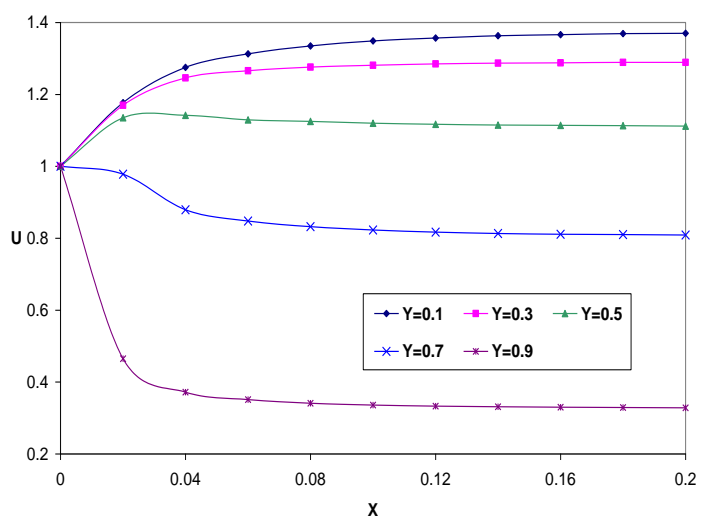

Figure 3: Velocity profile for fixed $M=2$ 


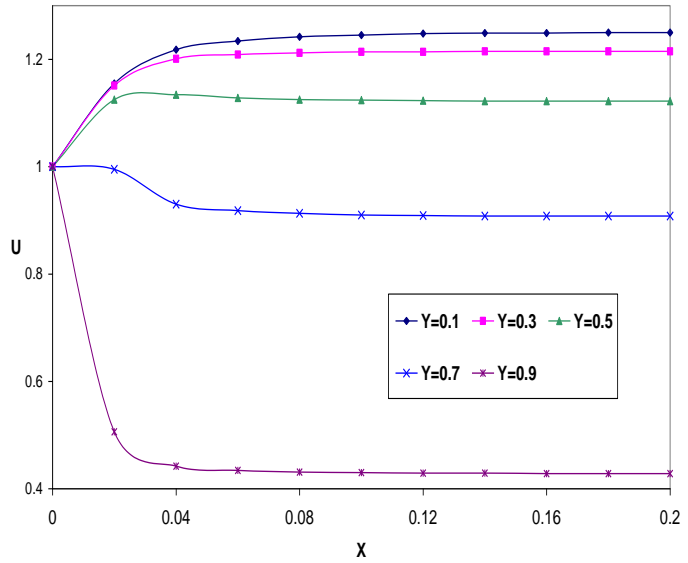

Figure 4: Velocity profile for fixed $M=4$

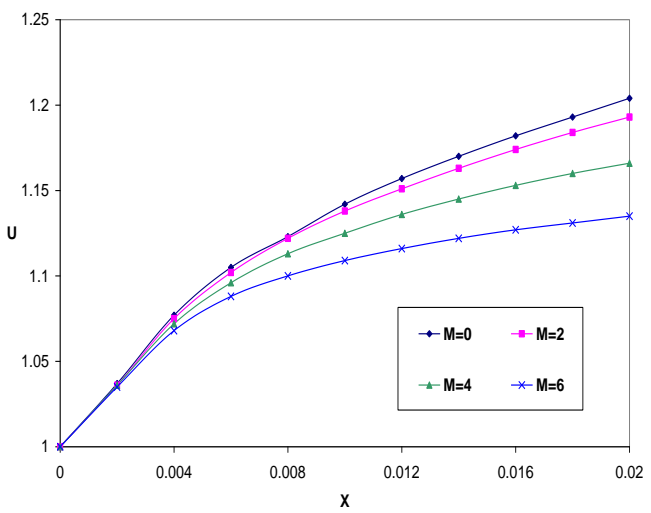

Figure 6: Velocity profile for fixed $Y=0.2$

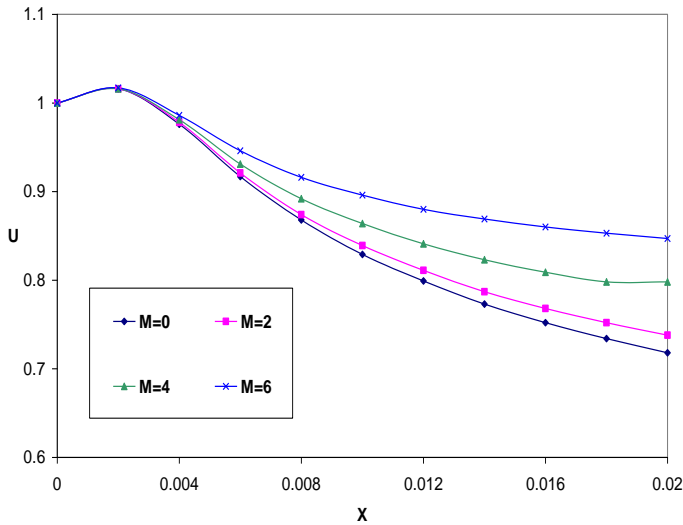

Figure 8: Velocity profile for fixed $Y=0.8$

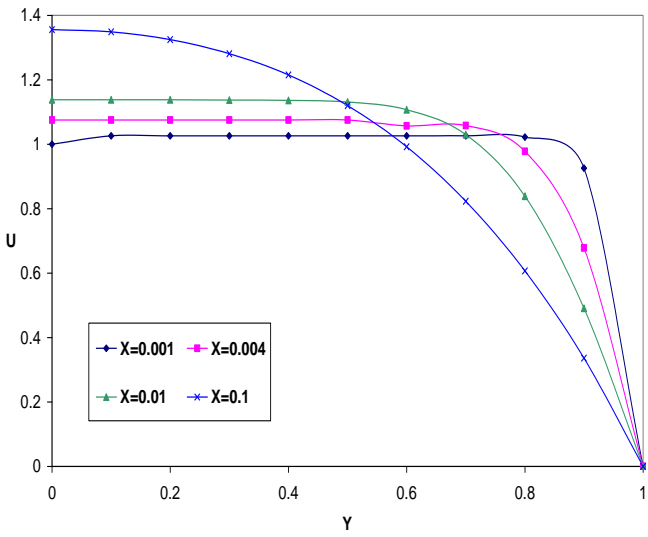

Figure 10: Velocity profile for fixed $\mathrm{M}=2$

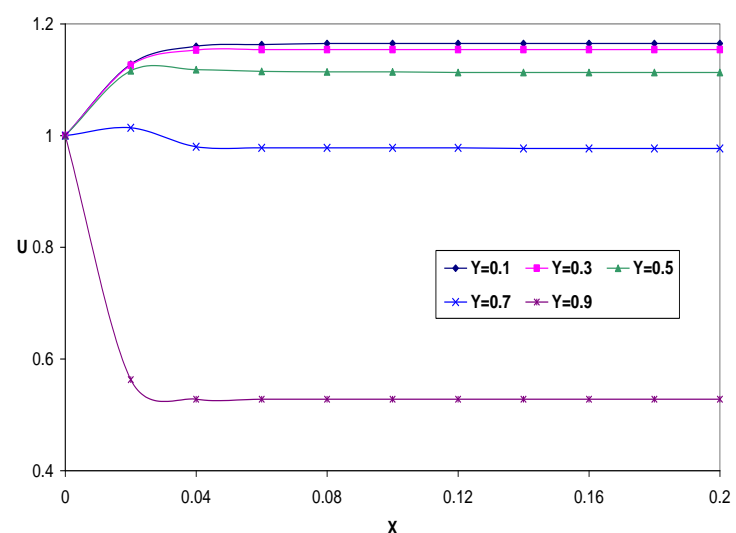

Figure 5: Velocity profile for fixed $M=6$

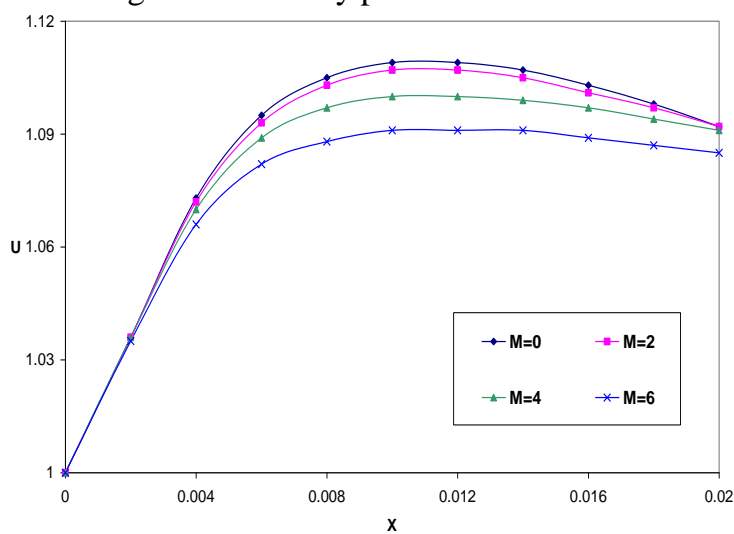

Figure 7: Velocity profile for fixed $Y=0.6$

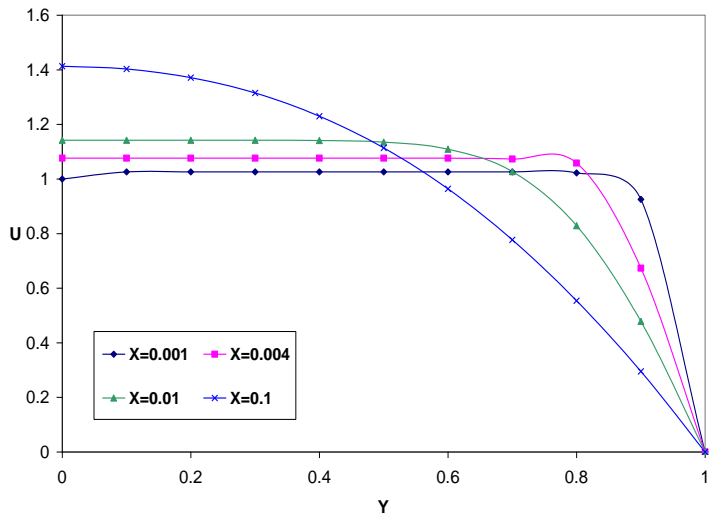

Figure 9: Velocity profile for fixed $M=0$

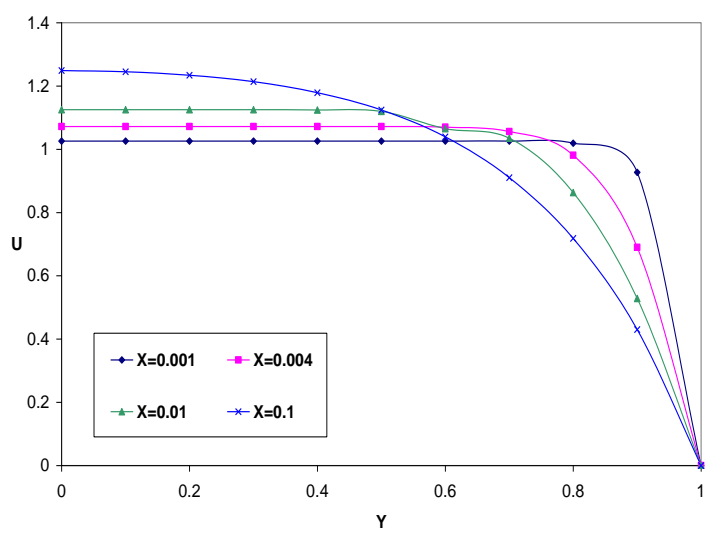

Figure 11: Velocity profile for fixed $M=4$ 


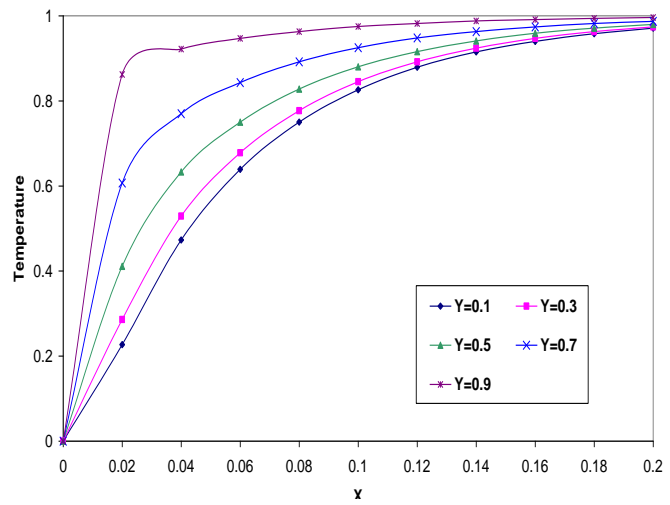

Figure 12(a): Temperature profile for fixed $M=0$ and $\mathrm{Ek}=0$

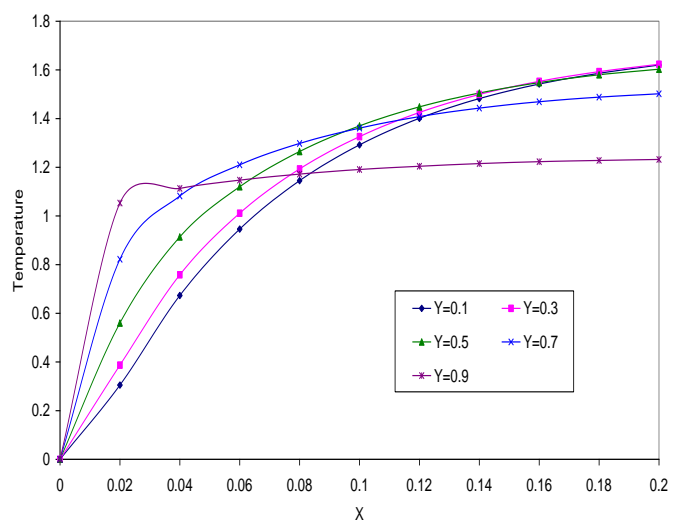

Figure 12(c): Temperature profile for fixed $M=0$ and $\mathrm{Ek}=10$

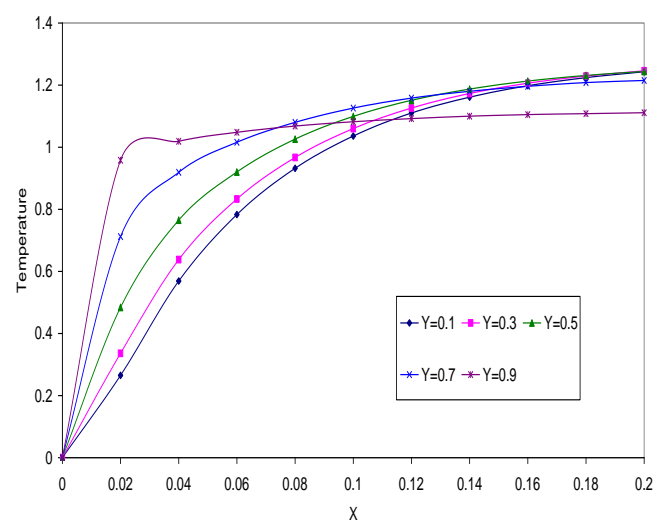

Figure 13(b): Temperature profile for fixed $M=2$ and $\mathrm{Ek}=5$

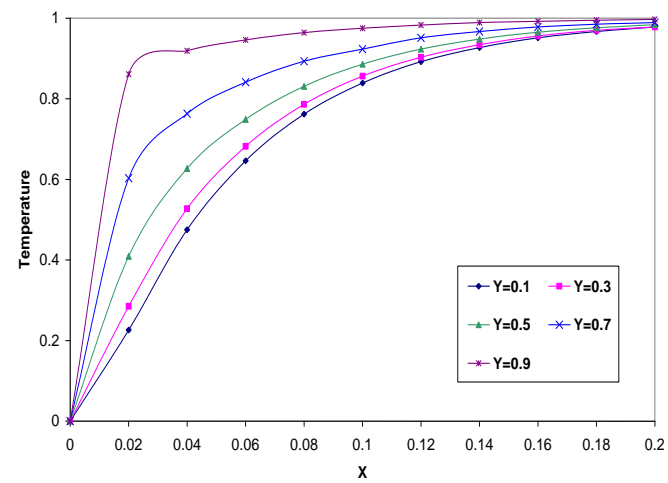

Figure 14(a): Temperature profile for fixed $M=6$ and $\mathrm{Ek}=0$

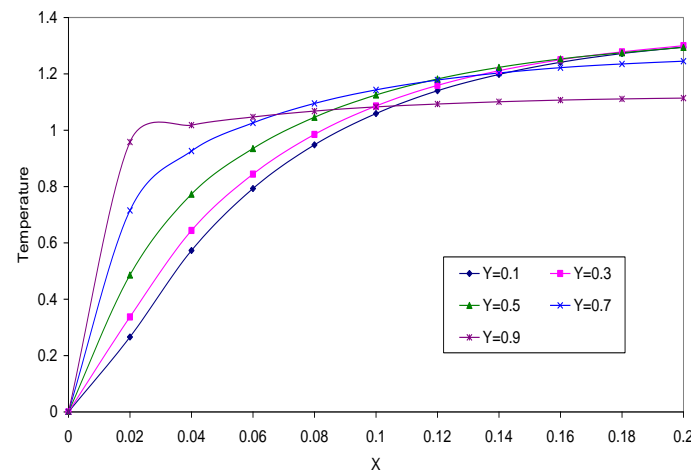

Figure 12(b): Temperature profile for fixed $M=0$ and $\mathrm{Ek}=5$

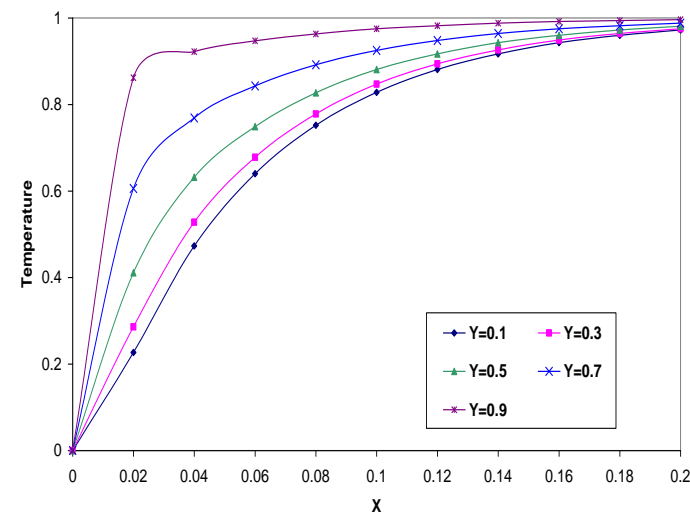

Figure 13(a): Temperature profile for fixed $M=2$ and $\mathrm{Ek}=0$

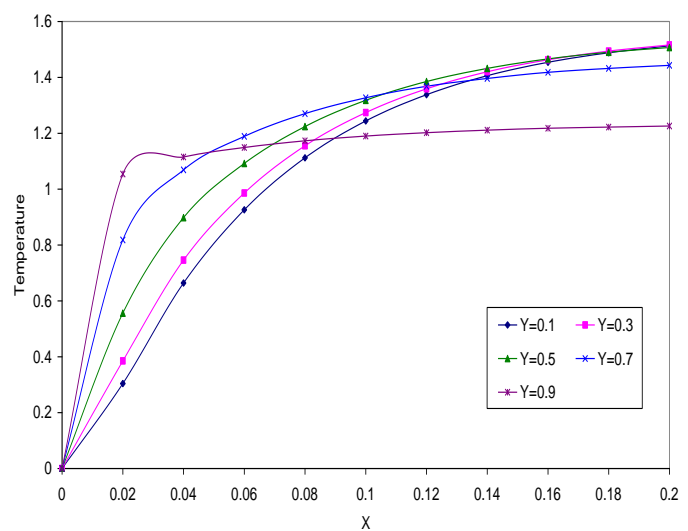

Figure 13(c): Temperature profile for fixed $M=2$ and $\mathrm{Ek}=10$

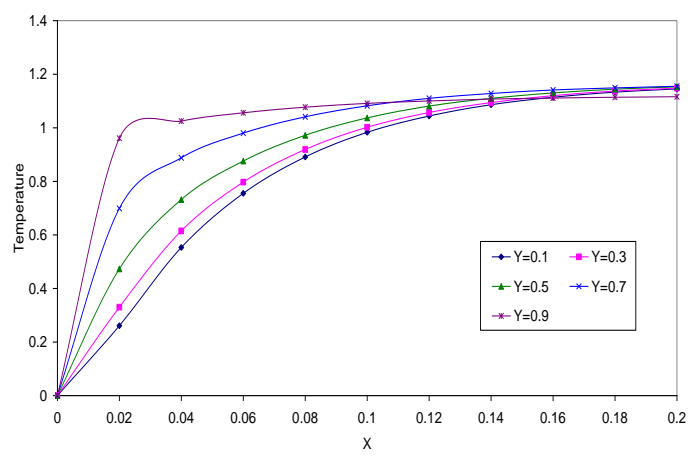

Figure 14(b): Temperature profile for fixed $M=6$ and $\mathrm{Ek}=5$ 


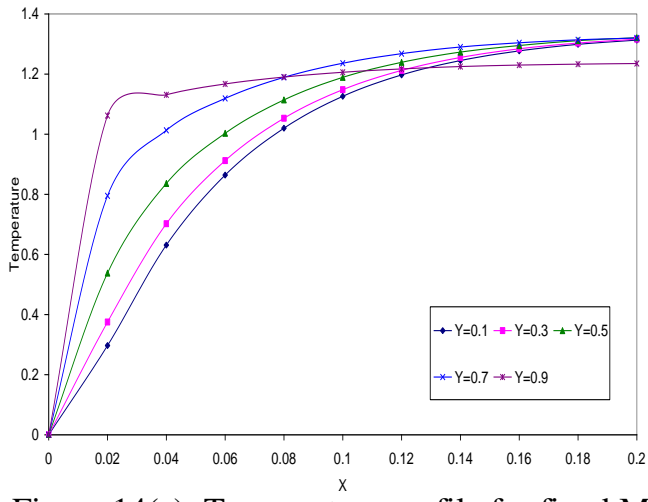

Figure 14(c): Temperature profile for fixed $M=6$ and $\mathrm{Ek}=10$

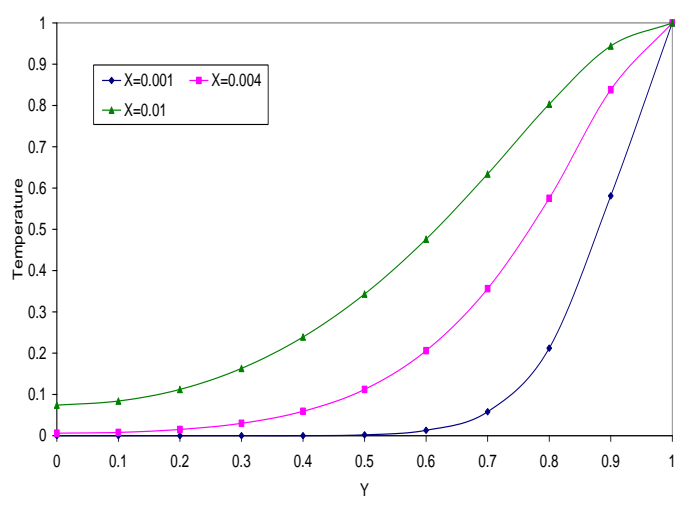

Figure 15(b): Temperature profile for fixed $M=0$ and $\mathrm{Ek}=5$

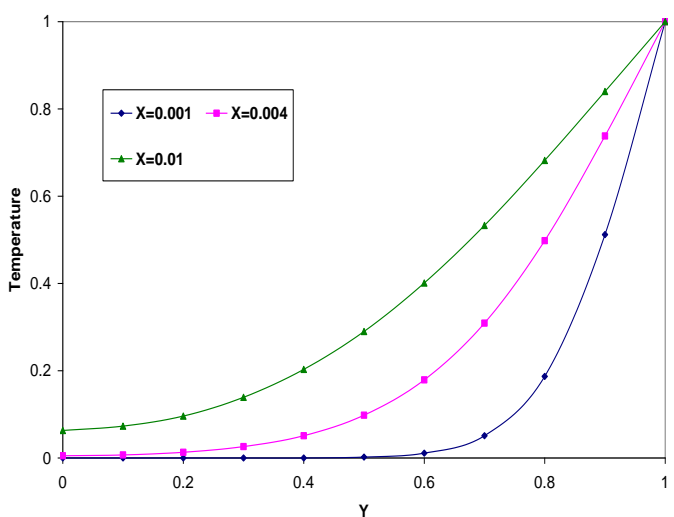

Figure 16(a): Temperature profile for fixed $M=2$ and $\mathrm{Ek}=0$

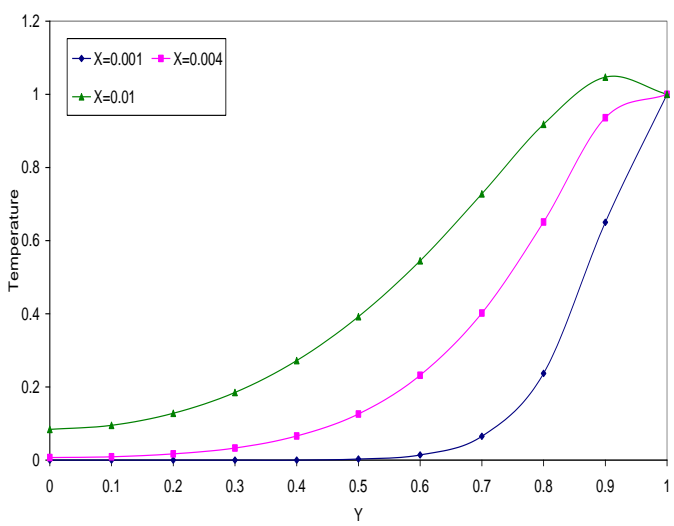

Figure 16(c): Temperature profile for fixed $M=2$



Figure 15(a): Temperature profile for fixed $\mathrm{M}=0$ and $\mathrm{Ek}=0$

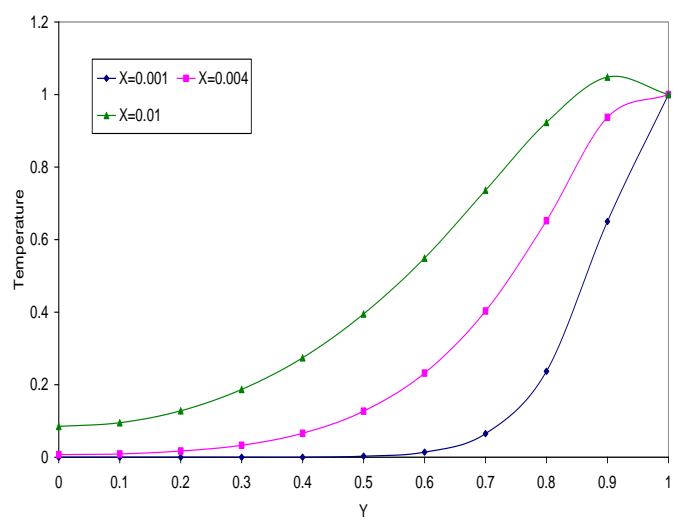

Figure 15(c): Temperature profile for fixed $\mathrm{M}=0$ and $\mathrm{Ek}=10$

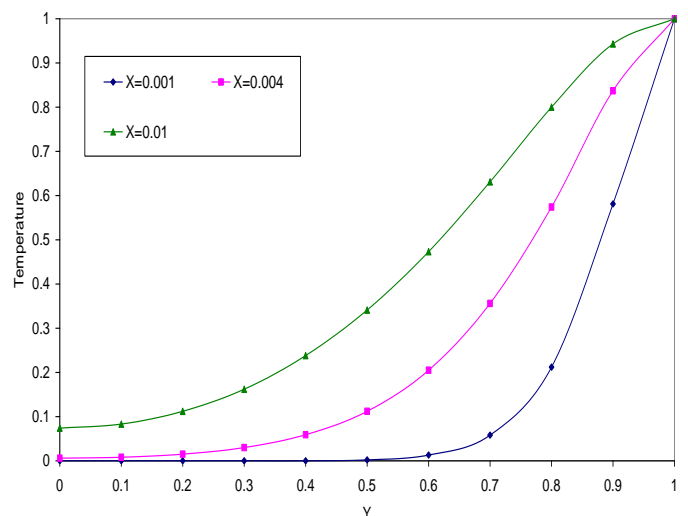

Figure 16(b): Temperature profile for fixed $M=2$ and $\mathrm{Ek}=5$

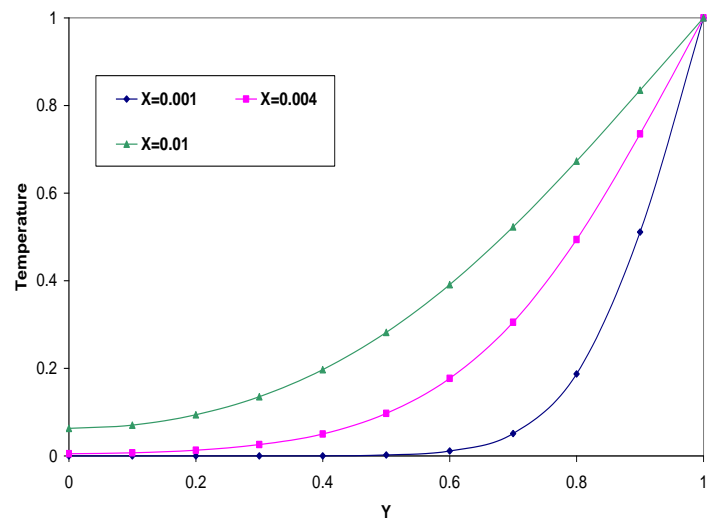

Figure 17(a): Temperature profile for fixed $M=6$ and 


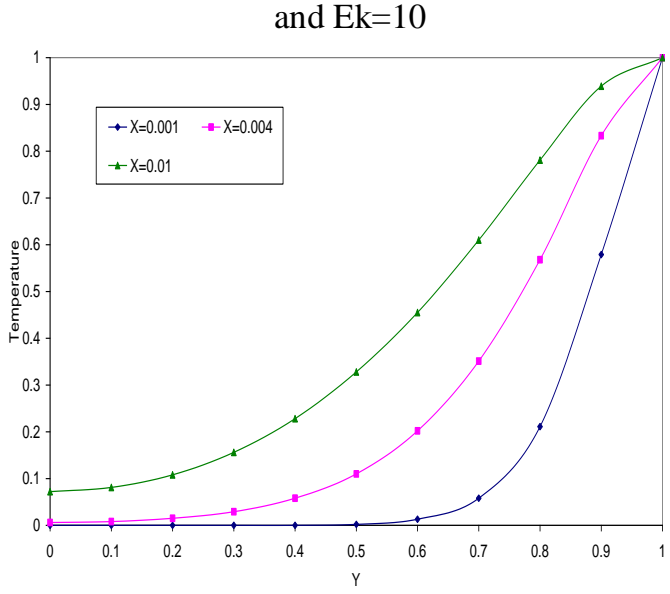

Figure 17(b): Temperature profile for fixed $M=6$ and $\mathrm{Ek}=5$

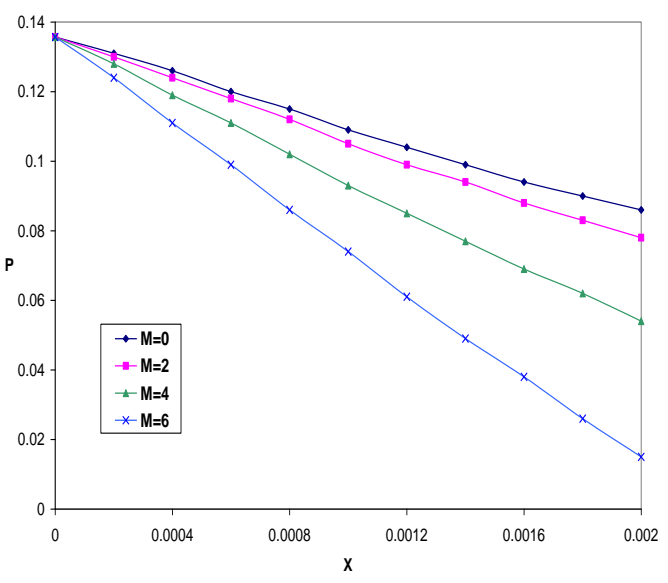

Figure 18: Pressure profile
$\mathrm{Ek}=0$

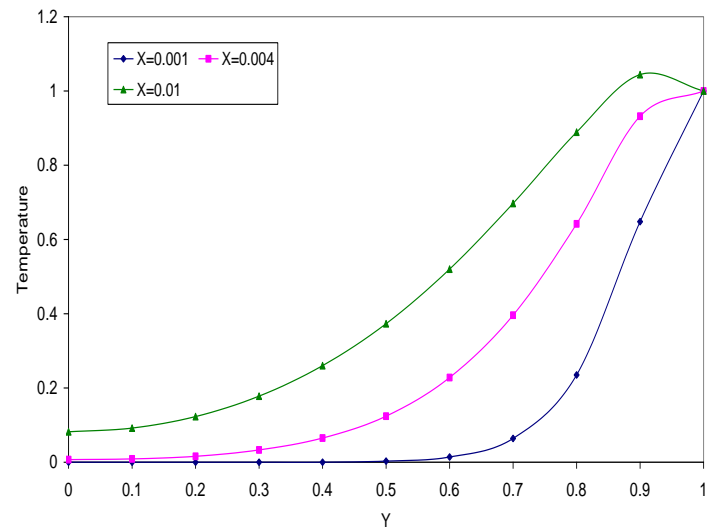

Figure 17(c): Temperature profile for fixed $M=6$ and $\mathrm{Ek}=10$

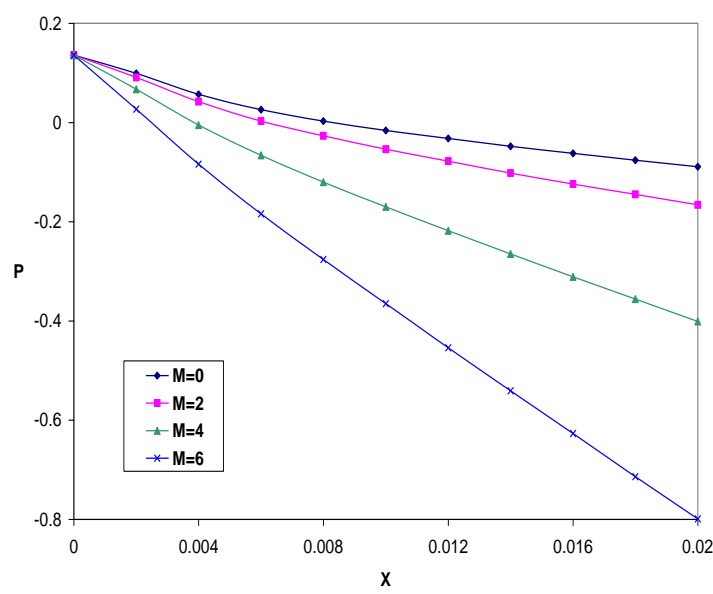

Figure 19: Pressure profile

\section{References}

[1] Alchaar, S., Vasseur, P., Bilgen., E. Numerical Heat Transfer. Part A, Applications Vol. 27 (1), pp. 107-127, 1996.

[2] Aldoss, T.K., Ali, Y.D., Al-Nimr, M.A. Numerical Heat Transfer. Part A, Applications Vol. 30 (4), pp. 379-396, 1996.

[3] Ali J. Chamkha, International Journal of Engineering Science, 42 (3.2), pp.217-230, 2004.

[4] Alireza, S., Sahai, V., Int. J. Heat Mass Transfer, Vol. 33, pp. 1711-1720 1990.

[5] Amkadhi M., Azzouzi. A and Hammouch. Z., Communicating in Nonlinear science and Numerical simulation, Vol.13, p.359, 2008.

[6] Angel, M., Pop, I., and Hossain, M. A., Applied Mechanics and Engineering, 4, pp.773-788, 1999.

[7] Anjali Devi, S.P., and Kandasamy, R., Int. Comm. Heat Transfer, Vol.29, p.707, 2000.

[8] Attia, H.A., Kotb, N.A., Acta Mechanica Vol. 117, pp. 215-220, 1996.

[9] Attia. H. A., Mechanics Research Communications Vol. 26, pp. 115-121, 1999.

[10] Bian, W., Vasseur, P., Bilgen, E., Numerical Heat Transfer. Part A, Applications Vol. 29 (6), 538-625, 1996.

[11] Blasius, H., Z. Angew, Math. U. Phys. 56, 1908.

[12] Bodoia, J.R. and Osterle, J.F., Appl. Sci. Res. A 10, 265, 1961

[13] Borjini, M. N., Kolsi, L., Daous, N., Aissia, H.B., Numerical Heat Transfer. Part B, Fundamentals Vol. 50 (2), pp.483-506, 2005.

[14] Borkakati, A. K., and Place S. Chakrabarty, Indian J. of Theoretical Physics, India, 47 (3.1), pp.43-60, 1999.

[15] Chen-Hsin Chen, International Journal of Engineering Science, 42 (3.7), pp. 699-713, 2004.

[16] Chion, J.S. and Kao, H.N., Appl. Math. Modelling Vol.18. p.679, 1994.

[17] Das, U.N., Aziz, A., and Ahmed, S., Place Far East J Appl. Maths., 3(3.3), pp. 263-286, 1999. [9]

[18] Deka, R.K., Das, U.N., Soundalgekar, V.M., Sarmah, A., and Takhar, H.S., Intl. J. of Heat and Technology, 17(3.1), pp. 71-73, 1999.

[19] Ghosh, S. K., International Journal of Engineering Science, 29 (3.8), pp.1013-1016, 1991

[20] Gonçalves, E., Faghri, M., Asako, Y., Charmchi, M., Numerical Heat Transfer. Part A, Applications, Vol. 47 (4), pp.315-332, 2005.

[21] Goren, S. L., Chem. Engg. Sci. 1 Vol.12, pp. 515, 1966.

[22] Hartmann, J. and Lazarus, F., Kgl. Danske Videnskab, Selekab, Matt - Phys, Medd. 15, No.6 and 7, 1937.

[23] Kayvan Sadeghuy, Navid Khabazi and Sayed Mohemmad Teghavi, International Journal of Engineering Science, Vol.45, p.923, 2007.

[24] Kazuyuki Veno and Shingeki Morioke, Fluid dynamics Research 12, 259, 1993.

[25] Lahjomri, J., Zniber, K., Ouberra, A., and Aleneny, A., Energy Conversion and Management, vol.44, p.11, 2003.

[26] Lima. A., Quaresma. N. N., Emanuel. N. Maccedo., International Communications in Heat Mass Transfer, Vol. 34, pp.420-431, 2007.

[27] Mohemmad Eissa Sayed Ahmed and Hazem Attia, Int. Comm. Heat transfer, Vol.20, p.1177, 2000.

[28] Nagarajan, A.S., Ph.D. Thesis, Osmania University, 1988. 
[29] Nanda, R. S., Sharma. V. P., Appl. Sci. Res. All., p. 279, 1962.

[30] Orhan Aydin and Mete Avci, Applied Energy, 83 (3.8), pp. 856-867, 2006.

[31] Ostrach, S., NACA TN No. 3, p. 141

[32] Raptis, A., and Kafousias, N.G., Canadian Journal of Physics, 60 (3.12), pp.1725-1729, 1982.

[33] Rossow, V.J., NACA - TN 3971, 1957.

[34] Seth, G. S. and Ghosh, S. K., International Journal of Engineering Science, 24 (7), pp.1183-1193, 1986.

[35] Sparrow, E.M., Cess, R.D., Trans. ASME J. Appl. Mech. Vol.29, No.1, p.181, 1962.

[36] Venkateswarlu, S., Rama Bhupal Reddy, B., and Siva Prasad, R., International Journal of Advanced Research in Engineering and Applied Sciences (IJAREAS), Vol.1, No.3, September 2012, pp.16-23.

[37] Yang, H.K. and Yu, C. P., International Journal of Heat and Mass Transfer, 17 (3.6), pp. 681-691, 1974. 